\title{
THE EFFECTS OF ACETYLCHOLINE AND METHACHOLINE UPON THE HUMAN COLON ${ }^{1}$
}

\author{
BY FRED KERN, JR.,2 AND THOMAS P. ALMY \\ (From the Department of Medicine, the New York.Hospital-Cornell Medical Center, \\ New York, N. Y.)
}

(Submitted for publication February 23, 1952; accepted March 24, 1952)

\section{INTRODUCTION}

The association of life stress, emotional conflict, and disordered function of the colon has often been observed clinically and has recently been confirmed by experimental observation on man $(1,2)$. Because of the established importance of the autonomic nervous system in the integration of reactions to stress, it has been assumed that the disturbed activity of the colon is directly caused by autonomic stimulation. Yet little is known about the effects of sympathetic or parasympathetic stimulation on the human colon. Since the musculature of the colon is innervated by post-ganglionic parasympathetic fibers, the effect on the bowel of acetylcholine, the chemical mediator of these impulses, is of considerable interest. Numerous investigators have observed that acetylcholine enhances tone and peristaltic activity of the stomach and intestines in experimental animals both in vitro and in vivo (3-5). Nothing is known of its effect on coordinated motor activity of the human gastrointestinal tract. We have, therefore, studied its effect on the motility of the intact human colon. We have also used acetyl-beta-methyl choline, a choline ester, which, because of its slower hydrolysis by cholinesterase, is effective after subcutaneous injection. This drug also differs qualitatively from acetylcholine in that it possesses muscarinic action only, lacking the nicotinic action of acetylcholine (6).

\section{MATERIALS AND METHODS}

Eighteen paid volunteer college students and medical students were the subjects for the experiments in which acetylcholine was administered. All were male and they

1 Supported in part by a grant from G. D. Searle \& Company, Chicago, and by the Zimmerman Colitis Fund. Presented in part before the American Federation for Clinical Research, Atlantic City, May 3, 1949.

${ }^{2}$ Lewis Cass Ledyard Fellow of the New York Hospital. ranged in age from 18 to 32 years. Methacholine was given to medical students, patients with diseases unrelated to the bowel, and patients with the irritable colon syndrome. These subjects ranged in age from 16 to $\mathbf{5 5}$ years; 16 were male, eight were female. The nature of the procedure and the subjective effects of the drug to be used were carefully and reassuringly explained to each individual prior to the experiment.

Sigmoid motility was recorded by a simple balloonkymograph technique previously described in detail (7). As preparation, each subject fasted six to 16 hours and the colon was emptied by one or two enemata of physiological saline two hours before the experiment. During a 30 to 60 minute control period, a sigmoid tracing was recorded and the blood pressure and pulse rate were measured by the usual clinical methods approximately every five minutes.

Methacholine ${ }^{3}$ (acetyl-beta-methyl choline chloride) was administered subcutaneously, 2.5 to $10 \mathrm{mgm}$. It was usually repeated in a larger or smaller dose within this range at least once in each subject. After the injection, blood pressure and pulse rate were recorded each minute until all signs and symptoms of drug effect had disappeared. The subject was carefully observed for other systemic effects and their presence or absence was recorded. Each subject received one or more injections of physiological saline as control, after which similar observations were made.

Acetylcholine was administered by continuous infusion at accurately controlled rates. A sterile solution of acetylcholine chloride in saline containing $100 \mathrm{mgm}$. of acetylcholine per cc. was prepared and stored in the refrigerator. From this stock solution the final dilution (5 or $10 \mathrm{mgm}$. per cc.) was prepared just prior to its use. The infusion apparatus consisted of two $250 \mathrm{cc}$. burettes, one filled with physiological saline, the other with the acetylcholine solution. These led to a three way stop-cock bearing the intravenous needle. The rate of flow was controlled by a tunnel clamp and a glass infusion meter ${ }^{4}$ placed in each system. A Murphy drip was also included in each system as an additional guide to the rate of flow. The actual amount of solution in-

3 The methacholine chloride and acetylcholine chloride were generously supplied by Dr. M. Carlozzi of Merck \& Co., Inc., Rahway, N. J.

4 Flowrator (Graubard-Peterson) manufactured by Fischer \& Porter Co., 350 Fifth Avenue, New York, N. $Y$. 
fused each minute was read from the burette at intervals of one or two minutes.

Shortly after starting the sigmoid motility tracing, the infusion was initiated with saline and continued for at least 30 minutes before the acetylcholine was administered. During this control period, blood pressure and pulse rate were recorded every five minutes, and during the acetylcholine infusion at one minute intervals, while detailed notes were made of the rapidly changing systemic effects upon the subjects. The infusion was begun slowly and the rate of flow increased stepwise. Increases in rate were halted when the subject experienced a moderate degree of respiratory distress and tachypnea. The intensity of these respiratory symptoms was approximately the same in all subjects. The infusion rate was then maintained constant, usually for five to eight minutes. The entire procedure lasted 10-15 minutes. If the rate of flow was increased too rapidly, unpleasant or potentially dangerous side effects occasionally developed, at which time the infusion was immediately terminated.

Subcutaneous methacholine and intravenous acetylcholine were also given to a number of subjects while fluoroscopic observations of the barium filled colon were being made. "Spot" films were taken of the cecum and sigmoid before drug administration and several times during the period of drug effect.

\section{RESULTS}

Effect of acetylcholine on the colon. Eighteen subjects received 21 acetylcholine infusions. In 15 of these experiments there was complete or almost complete abolition of sigmoid contractions
(Figure 1) ; in two experiments, there was a definite increase in contractile activity, and no detectable change occurred in four.

Acetylcholine infusions were administered to three subjects during fluoroscopic observations of the colon after it had been cautiously filled, but not distended, with barium sulphate suspension by enema. In two of these experiments, the right half of the colon was seen to contract vigorously, with simultaneous shortening, widening and disappearance of segmental contractions in the sigmoid and distal descending colon (Figure 2).

The effect of acetylcholine on the colon became apparent only when the rate of infusion was such that the other systemic effects were fully established. These effects were no less pronounced in subjects whose colon motility pattern was not altered.

Other effects of acetylcholine. As the acetylcholine infusion was initiated, the patient usually experienced a burning sensation at the site of the needle, which extended along the course of the brachial veins into the shoulder. The superficial veins often became dilated and purplish red. This pain became very severe at times, particularly when a drug concentration of $10 \mathrm{mgm}$. per cc. was used, but it always disappeared after two to three minutes, despite an increasing rate of infusion.

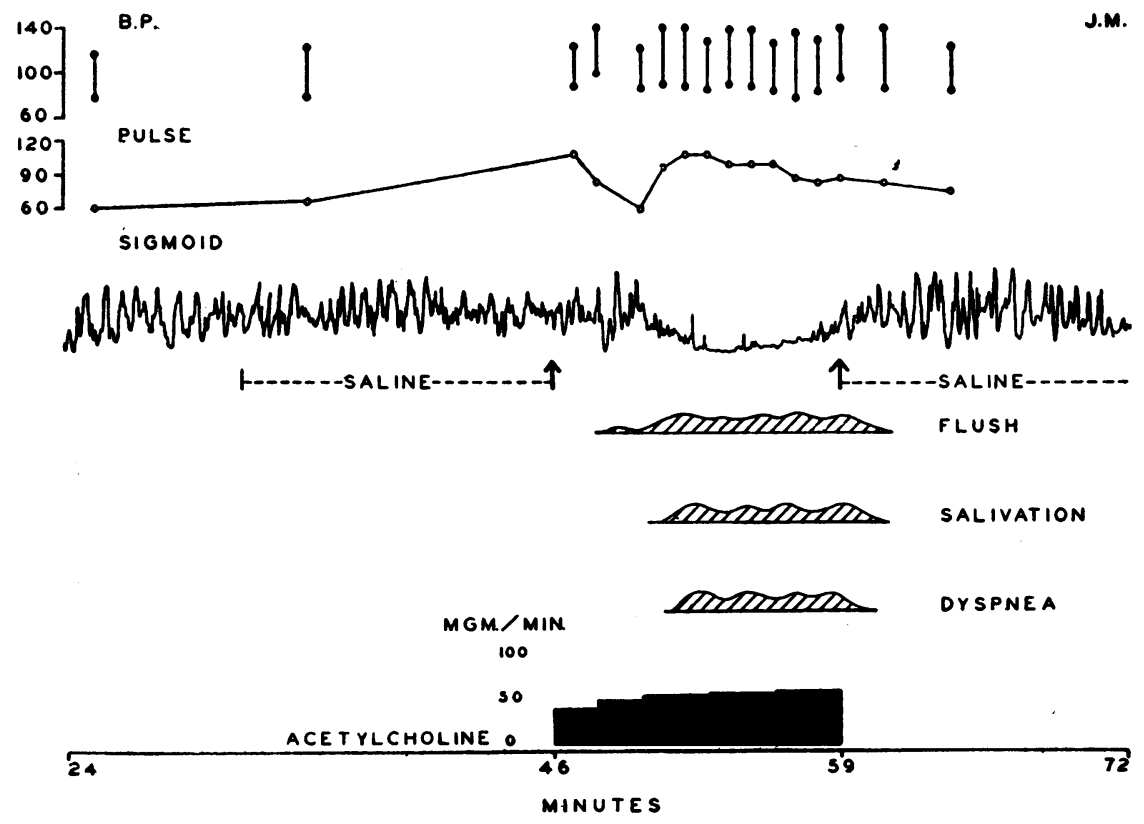

Fig. 1. Changes in Sigmoid Motility During an Infusion of Acetylcholine in a Normal Subject 
As the stepwise increases in rate continued, there developed a feeling of warmth over the face, and to a lesser extent elsewhere, associated with a flush limited to the face, the neck, and occasionally the chest. These were often, but not always, followed by variable amounts of visible sweating, and a slight increase in salivation. In some subjects there was slight lacrimation. As the rate was further increased respiratory difficulty, tachypnea, and often a desire to cough became manifest. It was at this rate of flow that the infusion was maintained. Despite the constant rate, there was considerable fluctuation of all signs and symptoms; the blood pressure and pulse rate varied unpredictably. There was an initial irregular rise in systolic and diastolic blood pressure in almost all subjects, followed by a fall below the control level in 13 ; often there was a fall in diastolic pressure only, with an increase in pulse pressure. In general the pulse rate varied directly with the diastolic blood pressure. In a few subjects there was no significant change in the blood pressure or pulse. If the rate of infusion was increased too rapidly, or if the level of tolerance was exceeded, hypotension, bradycardia, nausea, and occasionally uncontrollable coughing developed. A number of subjects experienced central nervous system effects, manifested by feelings described as "far away from everything" or "I am going to faint." These were not related to blood pressure or heart rate changes. After termination of the infusion all symptoms subsided abruptly and disappeared completely within two or three minutes.

The amount of acetylcholine necessary to achieve the desired level of drug effect varied from 40 to $120 \mathrm{mgm}$. per minute with an average of 72 . The total amount of acetylcholine given during an infusion varied from 505 to $1,270 \mathrm{mgm}$., averaging $739 \mathrm{mgm}$. The effective amount was independent of the weight of the individual.

Comment. This wide variation in individual tolerance to acetylcholine is in accord with the experience of Ellis and Weiss $(8,9)$. These authors infused acetylcholine intravenously into normal men and recorded systemic effects similar to those observed in these experiments. Carmichael and Fraser (10) also administered acetylcholine intravenously to human beings, but because of a different technique of administration their results are not comparable.

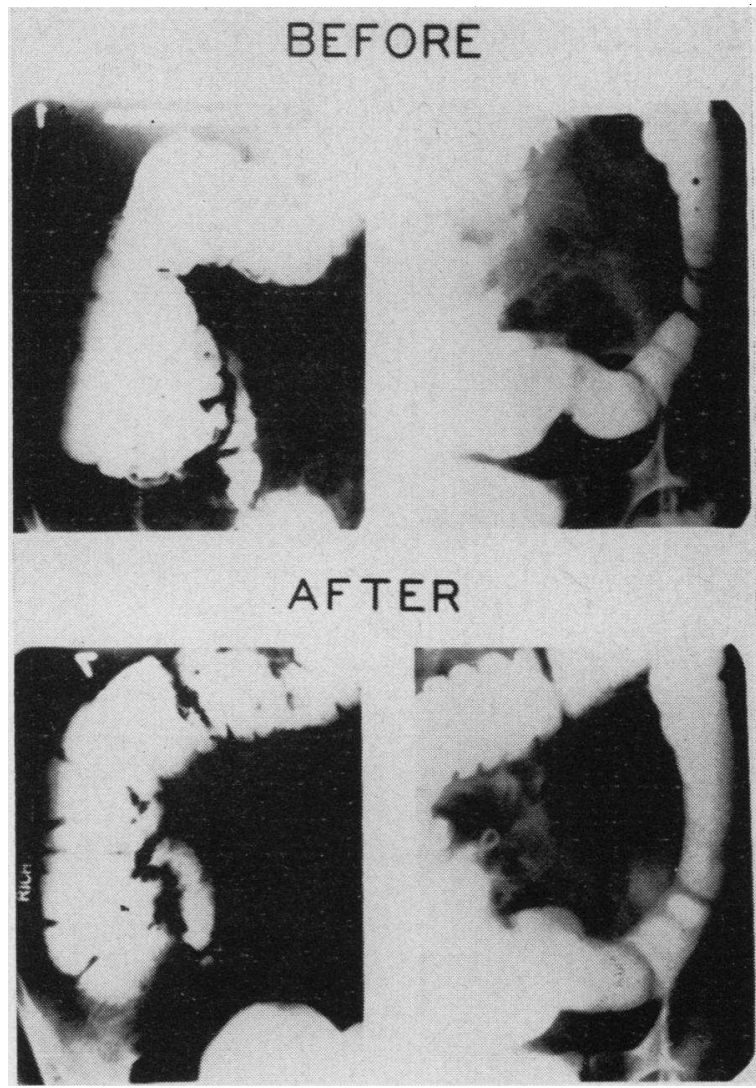

Fig. 2. Roentgenologic Appearance of the Right AND Left Portions of the Colon before Infusion of Acetylcholine and at the Height of the Effect of This Agent

Effect of methacholine on the colon. Methacholine was administered 49 times to 24 subjects. In 20 of these experiments, there followed a marked diminution or complete absence of wavelike motility of the sigmoid (Figure 3 ). In six experiments the results were inconclusive, and in 23 experiments there was no significant change after methacholine. In no instance did methacholine produce augmentation of sigmoid motility.

In five of the subjects in whom methacholine produced abolition of contractions of the sigmoid, the injection of methacholine was followed by the intravenous administration of $0.6-1.0 \mathrm{mgm}$. of atropine sulphate. This caused only a. brief interruption of sigmoid contractions, followed by a prompt return to the previous pattern. Thereupon the same or a larger amount of methacholine was again administered, and its effect upon sigmoid motility was blocked in each instance (Figure 4).

One subject with a transverse colostomy re- 


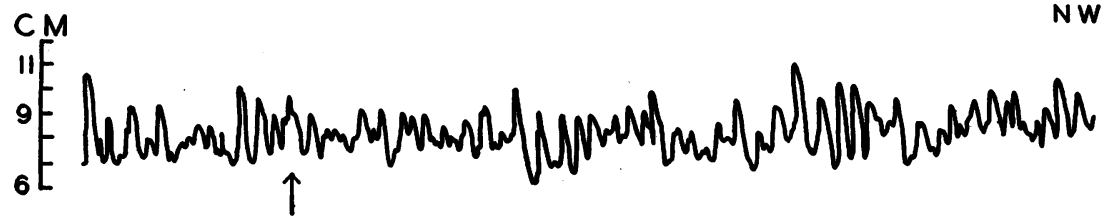

SALINE

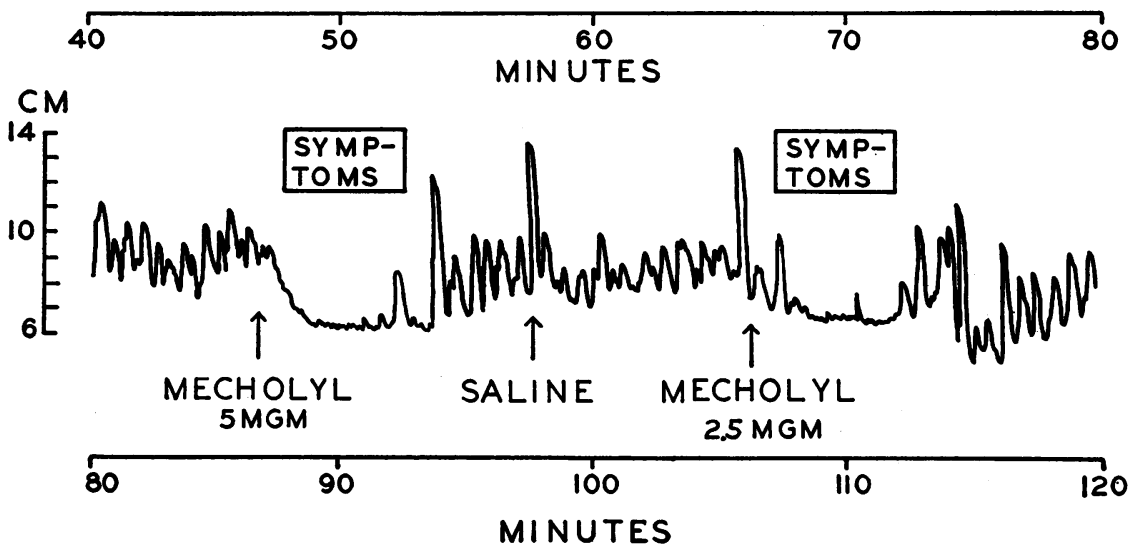

Fig. 3. Typical Effect of Subcutaneous Methacholine (Mecholyl@) Upon the Motility of the Sigmoid Colon

Control injections of saline produce no effect.
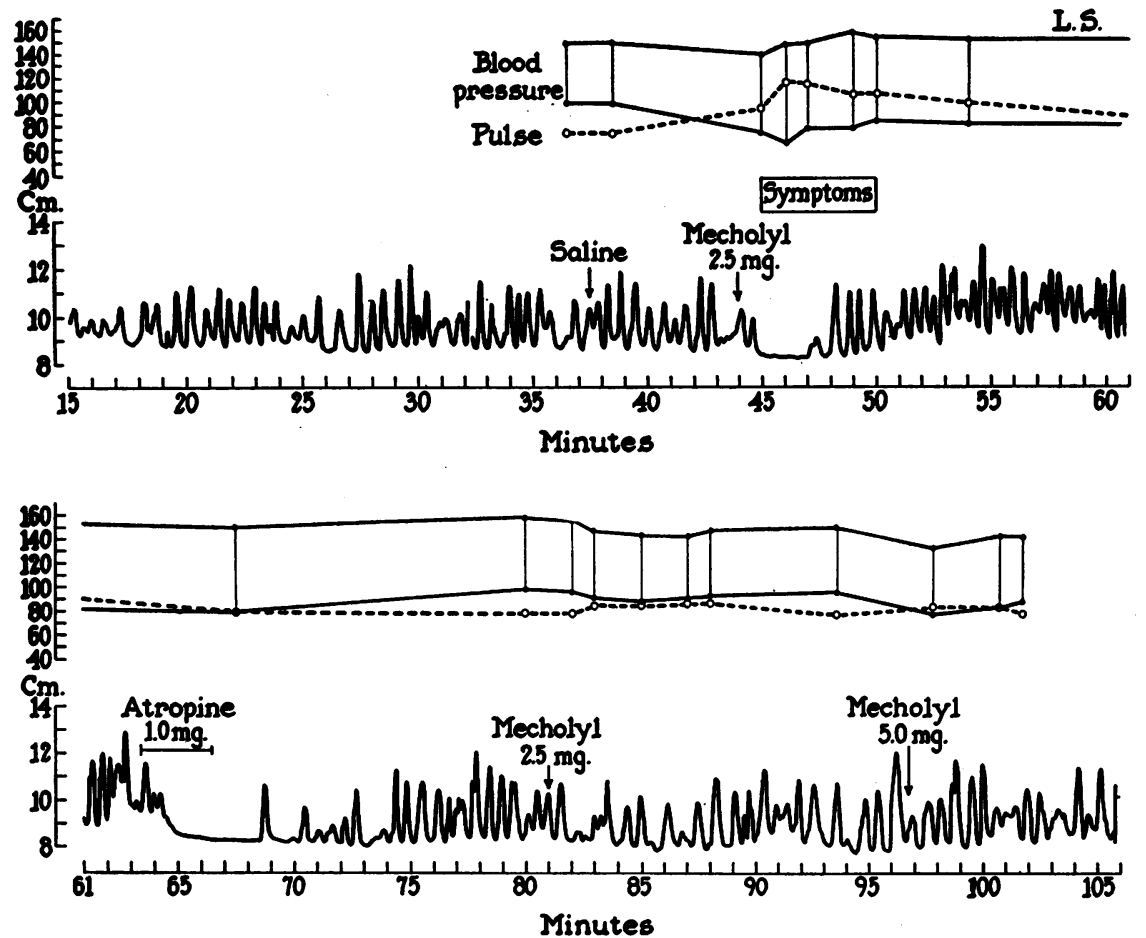

Fig. 4. Continuous Record of Human Sigmoid Motility, Demonstrating that after Intravenous Atropine, Methacholine fails to Affect the Sigmoid Motility, the Pulse, or the Blood Pressure 


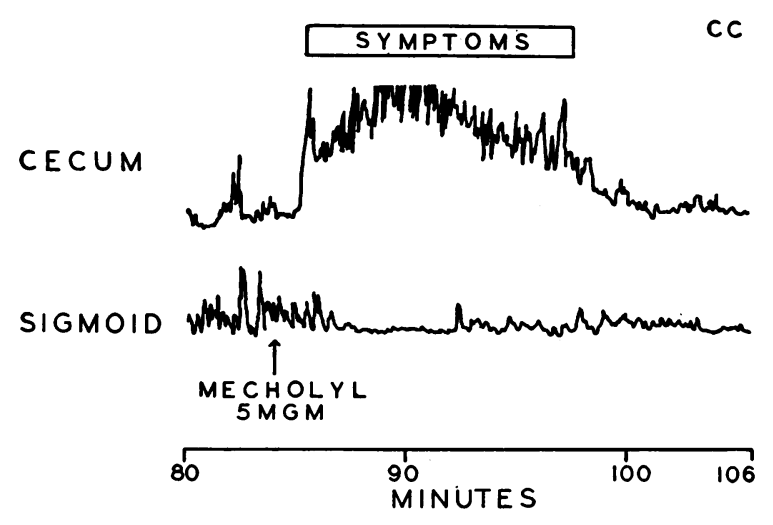

Fig. 5. Balloon-Kymographic Recordings of Motility of the Cecum and Sigmoid Colon, Showing Coordinate Action of Methacholine on these Regions OF THE BOWEL

ceived methacholine while motility tracings were being recorded simultaneously from a balloon in the sigmoid and a balloon in the cecum. There was a pronounced increase in activity in the cecum, resulting in the expulsion of feces from the colostomy, coincident with the abolition of sigmoid contractions (Figure 5).

Methacholine was administered subcutaneously to six subjects while the barium filled colon was observed fluoroscopically. In four of these, the right half of the colon contracted forcefully, while the distal colon shortened and widened. This response was identical with that produced by acetylcholine.

Other systemic effects of methacholine. The effects of methacholine on other structures were similar to those produced by acetylcholine. The flush was usually more intense, lacrimation more prominent, and respiratory embarrassment less marked. The blood pressure and pulse rate almost invariably rose to some extent. These systemic effects of subcutaneously administered methacholine have been described repeatedly ( 3 , $5,6,11)$, with a wide variation in individual sensitivity to the drug. This individual difference in intensity of effect, as well as the absence of effect on the colon in 23 experiments, may have been partly due to an irregular rate of absorption of the subcutaneously injected drug.

The alteration in sigmoid motility was not related to the intensity of these phenomena, but it was during their presence that the flattening of the tracing occurred. The subjects were never aware of abdominal cramps or intestinal activity.

\section{DISCUSSION}

In these experiments the usual effect of either acetylcholine or methacholine on the human colon was (1) abolition of phasic activity of the circular muscle of the sigmoid, (2) shortening and widening of the same segment, and (3) increased propulsive activity of the more proximal portions of the colon. These findings are compatible with those of Abbott (11) who found an increase in the overall pressure within the fluid-filled human colon of three out of six subjects following the injection of 5 to $15 \mathrm{mgm}$. of methacholine. Yet, they would seem to contradict extensive studies on the actions of these drugs in animals, in which they have augmented intestinal motility at all levels examined. This discrepancy can probably be explained by the difference in the anatomical and functional organization of the colon in man and in the usual herbivorous or carnivorous laboratory animals (12).

The stimulation of the intestine produced by acetylcholine in animals is considered a muscarinic effect. When intestinal motility in the atropinized animal is abolished by acetylcholine, the effect is regarded as due to its synaptic (nicotinic) action, with increased sympathetic stimulation of the gut. In our observations on the human sigmoid, however, both acetylcholine and methacholine abolished phasic activity. In the case of acetylcholine, this effect could be due either to its synaptic or to its muscarinic action, but since methacholine possesses only a muscarinic action, the response to this drug probably represents direct cholinergic stimulation of the smooth muscle. This conclusion is strengthened by the fact that the response was blocked by atropine. With both drugs, the reduction of sigmoid motility coincided with forceful contractions in the right colon and with extraintestinal signs of muscarinic activity, such as salivation, flushing of the skin, and usually a fall in blood pressure.

These coordinate actions of acetylcholine and methacholine on the proximal and distal colon seem appropriate for the propulsion of fecal masses and for the reception of these masses in the lower portions of the bowel. Hurst (13), observing the propulsion of feces in man by fluoroscopy, noted simultaneous abolition of circular muscle activity of the distal colon, shortening of the same segment, and massive contractions beginning 
either in the right colon or in the region of the splenic flexure. Galapeaux, Templeton, and Borkon (14), in producing diarrhea in dogs by the instillation of bile into the colon, observed a reduction in phasic activity of the distal colon. The same phenomenon has been observed in kymographic studies on the human sigmoid in patients with functional diarrhea (15). Moreover, in a recent study of patients with ulcerative colitis (16), those patients with severe diarrhea were found to have an absence or marked reduction of sigmoid contractions, while those without diarrhea had normal sigmoid motility. The similarity of the sigmoid motility patterns in diarrheal diseases with those induced by cholinergic stimulation suggests that sustained parasympathetic activity may be involved in the pathogenesis of these conditions.

\section{SUMMARY}

The effect of acetylcholine and methacholine upon the colon of normal individuals has been studied, using a balloon-kymograph technique to record the motility of the sigmoid, and (in one experiment) of the cecum. Acetylcholine was administered intravenously 21 times to 18 subjects, and methacholine was injected subcutaneously 49 times in 24 subjects. In 20 experiments with methacholine, and in 15 experiments with acetylcholine, these drugs abolished the phasic contractions of the sigmoid. Acetylcholine augmented sigmoid contractions in two experiments, and methacholine in none.

In nine experiments, the entire colon was observed by fluoroscopy and spot roentgenograms. In these, at the time of disappearance of sigmoid contractions, the sigmoid appeared to shorten and the right colon contracted vigorously. This coordinate pattern of motor activity, produced by cholinergic drugs, is similar to that which occurs spontaneously during mass peristalsis.

The sigmoid motility response to acetylcholine and methacholine is identical with that observed in association with diarrhea in man and animals. This may help to define the role of the parasympathetic nervous system in the mechanism of functional diarrhea and of ulcerative colitis.

\section{ACKNOWLEDGMENT}

The authors are indebted to Miss Natalie Stolk for invaluable technical assistance.

\section{REFERENCES}

1. Almy, T. P., Experimental studies on the irritable colon. Am. J. Med., 1951, 10, 60.

2. Almy, T. P., Kern, F., Jr., and Abbot, F. K., Constipation and diarrhea, as reactions to life stress. A. Res. Nerv. \& Ment. Dis., Proc., 1950, 29, 724.

3. Molitor, H., A comparative study of the effects of five choline compounds used in therapeutics : acetylcholine chloride, acetyl beta-methylcholine chloride, carbaminoyl choline, ethyl ether beta-methylcholine chloride, carbaminoyl beta-methylcholine chloride. J. Pharmacol. \& Exper. Therap., 1936, 58, 337.

4. Koppanyi, T., Acetylcholine as a pharmacological agent. Bull. Johns Hopkins Hosp., 1948, 83, 532.

5. Wolff, L. H., Effect of certain parenterally administered drugs on the colon of the dog. Am. J. Digest. Dis., 1939, 6, 243.

6. Simonart, A., On the action of certain derivatives of choline. J. Pharmacol. \& Exper. Therap., 1932, 46, 157.

7. Kern, F., Jr., Almy, T. P., and Stolk, N. J., Effects of certain antispasmodic drugs on the intact human colon, with special reference to banthine ( $\beta$ diethylaminoethyl xanthene-9-carboxylate methobromide). Am. J. Med., 1951, 11, 67.

8. Ellis, L. B., and Weiss, S., The study of the cardiovascular responses in man to the intravenous and intra-arterial injection of acetylcholine. J. Pharmacol. \& Exper. Therap., 1932, 44, 235.

9. Weiss, S., and Ellis, L. B., The comparative effects of the intravenous administration to man of acetylcholine and acetyl- $\beta$-methylcholine. J. Pharmacol. \& Exper. Therap., 1934, 52, 113.

10. Carmichael, E. A., and Fraser, F. R., The effects of acetylcholine in man. Heart, 1933, 16, 263.

11. Abbott, W. O., Acetyl-beta-methylcholine. II. The action on the gastro-intestinal tract of normal persons, in abdominal distention, and in certain other conditions. Am. J. M. Sc., 1933, 186, 323.

12. Alvarez, W. C., An Introduction to Gastro-Enterology. Paul B. Hoeber, Inc., New York, 1948, 4th ed., p. 570 .

13. Hurst, A. F., Constipation and Allied Intestinal Disorders. H. Frowde, London, 1909.

14. Galapeaux, E. A., Templeton, R. D., and Borkon, E. L., The influence of bile on the motility of the dog's colon. Am. J. Physiol., 1938, 121, 130.

15. Almy, T. P., Abbot, F. K., and Hinkle, L. E., Jr., Alterations in colonic function in man under stress. IV. Hypomotility of the sigmoid colon, and its relationship to the mechanism of functional diarrhea. Gastroenterology, 1950, 15, 95.

16. Kern, F., Jr., Almy, T. P., Abbot, F. K., and Bogdonoff, M. D., The motility of the distal colon in non-specific ulcerative colitis. Gastroenterology, 1951, 19, 492. 